\title{
La política cotidiana que sirve a la gente. Una mirada alternativa de la práctica de los profesionales en lo social
}

\author{
The daily policy that serves people. An alternative view of the practice of social \\ professionals \\ Melina Engler \\ Universidad de Chile
}

\section{Aprender a trabajar con la gen- te para mejorar la calidad de vi- da de la comunidad}

El pensamiento occidental arraiga profundo en nuestras prácticas profesionales. Estamos acostumbrados a lidiar con modelos e ideales que debemos ejecutar, apresurándonos a tensar la realidad en determinado sentido, como si la realidad misma no estuviese ya hilvanada por el sentido desde el vamos.

Cuando armamos equipos de trabajo en los $\mathrm{Mi}-$ nisterios de Acción Social, en las Secretarías de Desarrollo Social, en los programas de asistencia social; tendemos a pensar comúnmente en estrategias que "contengan la pobreza".

Como nos enseñaba a los equipos de trabajo el psicólogo argentino Sebastián Bertucelli, practicamos el ritual de la conquista que hemos padecido nosotros mismos como pueblos latinoamericanos: 1) vamos al lugar donde vive la gente, 2) la sacamos de su lugar porque no está viviendo correctamente, 3) hacemos una casa nueva en la casa de la gente, 4) los implantamos de vuelta en el lugar y les enseñamos cómo vivir correctamente. Y el círculo se cierra cuando el profesional vuelve a su clase de referencia, como "investigador" para escribir una tesis o trabajo sobre la mejora social que supuestamente realizó.

Esta forma de intervención tenemos que combatirla a diario. Por eso debemos retornar una y otra vez a la noción de comunidad: el que habita con el otro, sabe de la alegría, del padecer y del cansancio cotidiano del otro.

Un posible primer principio en el trabajo comunitario es aquel que dispone: uno ingresa al sistema (familiar) por donde el sistema lo permite. Con humildad. Cuando se acerca uno a la gente del vecindario, pensando en ayudar con sus problemas, tiene la falsa premisa que debe "asistir al otro", como si se tratara de un cuerpo inerte del que se debe alte-

*Dirección de correspondencia [Correspondence address]: Melina Engler, Universidad de Chile

E-mail: meli13engler@hotmail.com rar su trayectoria. La familia le da o no entrada al profesional. Es el grupo familiar el que decide cuál será el ingreso de uno. Y uno se presta a respetar esas coordenadas.

Urie Brofenbrenner (1986) cuando habla del desarrollo humano dice es "un cambio perdurable en el modo que una persona percibe su ambiente y se relaciona con él". Los trabajadores de lo social encontramos utilidad en sus aportes sobre ambientes ecológicos, es decir, disposiciones seriadas de estructuras concéntricas, donde se puede identificar:

- Microsistema: el patrón de actividades, roles y relaciones interpersonales que la persona en desarrollo experimenta en un entorno determinado, con características físicas y materiales particulares. b) Mesosistema: compuesto por las interrelaciones entre dos o más entornos en los que la persona participa activamente. Es un sistema de microsistemas. Se forma o se amplía cuando la persona entra en un nuevo entorno.

- Exosistema: uno o más entornos que no incluyen a la persona como participante activo, pero en los cuales se producen sucesos que afectan a lo que ocurre en el entorno que comprende a la persona, o que se ven afectados por lo que ocurre en este entorno.

- Macrosistema: correspondencias, en forma y contenido, de los sistemas de menor orden que existen o podrían existir en el nivel de la subcultura o de la cultura en su totalidad, así como el sistema de creencias o ideología que las sustenta.

Para la perspectiva ecológica, es posible entender la disfuncionalidad del nivel social como las consecuencias de una inadecuada interacción entre la familia y los contextos ambientales, tales como las dificultades de escolarización de los niños y jóvenes, ausencia de vínculos entre la escuela y la familia (ausentismo y fracaso escolar), desempleo de los o las jefes o jefas de familia, condiciones de pobreza crónica a causa de su procedencia sociocultural y ausencia de recursos económicos en las familias (marginación y exclusión social). 
Las perspectivas ecológicas nos ayudan a entender los comportamientos, las costumbres, los rituales y los patrones de conductas "no sanas" quitándole a nuestro accionar prejuicios y juicios de valor condenatorios que laceran la dignidad de quien tocan.

En segundo lugar podríamos señalar que la tarea que vamos a desarrollar nos orienta y nos protege. ¿De qué nos protege? De nosotros mismos, de la omnipotencia de pensar que podemos resolver la vida de la gente. Con la tarea modesta bien clara en la cabeza, no nos dispersamos para escuchar más de lo que nos quieren contar ni para hacer más de lo que el otro dispone. Evita que nos extraviemos.

Esto que puede resultar de una sencillez zonzona es de difícil retención en nuestros esquemas operativos. Solemos actuar como si el otro fuera pobre víctima? doble víctima por ser pobre y por estar indefenso -al que hay que rescatar, incluso de sí mismo.

El tercer principio, que bien podríamos ubicar como primero, es que la población ya está en movimiento. Es decir, tiende naturalmente a la salud. Las familias en riesgo ya están buscando alternativas a sus problemas cuando nosotros llegamos como profesionales a prestar ayuda. La pregunta no es cómo incluir a la gente en lo que yo traigo, sino cómo incluirse uno en lo que la gente ya está haciendo.

Como la solución a la vida de gente no pasa por uno, hay que aprender a trabajar sin concentrar el poder, y esto que llamamos heterarquía. En situaciones de riesgo social resuelve quien sabe y puede. Lo importante es que se haga, no quién lo hace. El que padece el problema lo sabe en primera persona, tiene urgencia por solucionarlo, no importa quién se lleva el mérito. Hay que prescindir de la importancia personal.

El conocimiento en acción del profesional es de índole ética más que técnica, es decir, se trata de un saber cómo realizar una forma ética en vez de cómo conseguir determinados estados finales anticipados como resultados últimos de una acción. También debemos aprender a coordinarnos, porque estamos acostumbrados a intervenir en impecable no coordinación con los demás. Así no es infrecuente que actuemos sin tener en cuenta operaciones previas, sin comunicarse con otros equipos que ya están trabajando con la familia.

En cuarto lugar, precisar que las redes son de la gente, no las crea el profesional social. Una y otra vez nos dicen en seminarios y congresos "armemos redes", cuando las redes en las comunidades ya están andando desde hace rato. Uno se apoya en lo preexistente porque así la intervención se despliega más rápido, pero no las arma ni el psicólogo, ni el médico, ni el trabajador social. Uno tiene que aprender a ver vínculos, cosa que es difícil porque ha sido entrenado en la universidad en detectar patologías y carencias, no elementos salutíferos. Parte de la idea que la gente tiene problemas y discapacidades, no potenciales latentes.

Quinto principio, la manera más inocua de comenzar a trabajar con familias en situación de riesgo es a través de los programas de cobertura sanitaria básica de la población, o de atención primaria de la salud. Desde ahí el profesional, no importa cuál sea su disciplina, puede trabajar con la familia sin irritar.

Esta entrada oblicua, es la única que evita que la familia haga lo que cualquiera de nosotros haríamos si vienen a meterse en nuestras vidas: cerrar la puerta. No se entra por la violencia, por la delincuencia, por la toxicomanía; se ingresa a la dinámica de resolución del problema por lo que la familia puede hacer.

Concomitante, el seguimiento sistemático es la pieza clave para que la intervención social no resulte un picoteo. Una vez que uno empezó a trabajar con una familia puesta en cobertura, sigue adelante en espera activa. ¿Qué significa esto? No es llamar constantemente o investigar sobre su situación sino de forma respetuosa estar atento a la evolución del proceso.

Un profesional de lo social, no debe practicar intervenciones iatrogénicas. Estas consisten en alterar las pautas del sistema familiar, desestructurando vínculos previos en nombre de un supuesto bienestar que se presume del otro. Un caso claro es cuando trabajamos con familias que tienen un miembro en la cárcel y que se evalúa tradicionalmente como "vínculo nocivo" para el crecimiento de los niños.

Y entonces... ¿cómo intervenimos en lo cotidiano? ¿Qué debemos cuidar que suceda o que no suceda? El filósofo y sinólogo francés Francois Jullien (1996) nos introduce al pensamiento oriental, profundamente respetuoso de la lógica de los procesos, pensando el mundo como dispositivo con un ideal de regulación. Plantea la necesidad de examinar en detalle el punto de partida de la tendencia: si hay desviación corregir de inmediato porque se acentúa, si la tendencia conviene, descansar en ella. Estos conceptos confieren un marco para el diseño de intervenciones sociales que siguen y respetan la tendencia de la realidad y los procesos que ya se están dando en la familia. El profesional simplemente ayuda a catalizar, destrabar, escuchar, facilitar un cambio que ya estaba contenido en potencia en 
el grupo familiar.

En sexto lugar, es posible señalar que el elemento básico de nuestro trabajo es la confianza que nos tiene la gente. Confianza que no se da de un día para el otro, sino que lleva su tiempo y sus tanteos progresivos. Para poder incidir en las problemáticas psicosociales de las familias tenemos que construir vínculos de confianza previos. De ahí la importancia de posicionar equipos territoriales en las áreas más complicadas de los territorios para construir inserción en la comunidad.

Trabajar desde las redes es mucho más poderoso que desde las instituciones. Las instituciones funcionan de acuerdo a sus objetivos, no a los objetivos de la gente. Una vez creadas se cristalizan en "modos de", que nada tienen que ver con la manera en que respira y se mueve la comunidad.

\section{Políticas sociales para nuestros pueblos latinoamericanos}

Los recursos destinados a la política social suelen ser buena metáfora de lo escaso entre lo escaso. Y de lo mal repartido o pobremente asignado. Agudizada la situación en nuestros países después de años de neoliberalismo y de recorte presupuestario de un Estado presumido ineficiente.

Nuestros pueblos han padecido acciones suscriptas a la rúbrica de "focalización del gasto" y de "ajuste con rostro humano". Por eso, porque sabemos que no tenemos posibilidades económicas ilimitadas, más que focalizar la política social, resulta interesante diseñar dispositivos para áreas estratégicas; armar equipos de profesionales y destinar recursos (materiales, horas de trabajo, edilicios) en aquellas áreas donde están concentrados los problemas sociales.

Esto resulta para ciudades de cualquier tamaño y geografía: armamos micropolíticas sociales para poblaciones en riesgo. ¿Y cómo se diseñan? Siendo sistemáticos en el tratamiento de la información. Utilizando herramientas tecnológicas, construyendo mapas interactivos que nos indiquen dónde están concentrados los problemas sociales.

¿Para qué quedarnos atendiendo desde programas selectivo-normativos si la población que necesita ayuda es una sola y la misma? El mapa, la georreferencia como sistema metódico y ordenado rompe inmediatamente con las "quintas" que nos tientan a los profesionales; impide que nos especialicemos inútilmente en "temas": violencia familiar, adolescencia en conflicto, marginalidad, etc. cuando la familia es propiamente un sistema interconectado y una vez que comenzamos a trabajar con ella los efectos se replican como bucles que no se limitan a estas categorías.

No hay diferencias entre salud mental, salud pública y bienestar social. Es todo lo mismo. En nuestros pueblos latinoamericanos, las condiciones de vida son elementos propiciadores de salud y enfermedad, por lo que no podemos pensar intervenciones profesionales aisladas. En áreas de riesgo es necesario que actúen equipos interdisciplinarios, compuestos por médicos, enfermeras, trabajadores sociales, psicólogos y toda otra profesión que resulte pertinente para la clase de problema que se intenta resolver. Esto es importante para destacar: la índole del problema determina la configuración del equipo y la designación de las profesiones, no viceversa.

\section{Detectar tempranamente la problemática}

La georeferencia con un sistema computarizado permite visualizar con mayor precisión la movilidad en el tiempo de áreas de riesgo y/o confirmar otras en su estabilidad siempre relativa.

Primero se atiende aquellas que representan un mayor riesgo, y luego cuando se va ganando calidad en la cobertura, se arrima uno a las siguientes, por aproximaciones sucesivas. En este sentido es muy importante la detección anticipada de poblaciones que van creciendo por migraciones internas y externas y que ponen en jaque a los servicios de salud que no están preparados para afrontar estos crecimientos.

El mapeo sistemático de los problemas de la población permite tomar decisiones más ajustadas en la asignación de recursos, y así plegar y desplegar dispositivos y equipos de acuerdo a las necesidades de la gente.

\section{Equipos profesionales con áreas de responsabilidad a cargo}

Los Servicios Sociales trabajan con el concepto de área de cobertura, por lo que se evita que puedan "expulsar" algún caso que entra dentro de su área de responsabilidad así como darle un sentido y criterio para operar por avance progresivo. Los servicios montados pueden a su vez observar en los mapas cuál es la evolución de la situación epide- 
miológica de la población y realizar los ajustes precisos en su propia intervención.

Precisamos abandonar la noción de Servicios Sociales tradicional, es decir, con carácter benéficoasistencial, compensatorio, para pasar a Servicios que ponen a disposición de la población, que facilitan, elementos para su desarrollo. Esto demanda la gestación de Servicios Sociales cambiantes, acordes a la población que se mueve, es decir, nace, crece y muere.

En políticas sociales es más poderosa la gestión de datos ubicados geográficamente antes que promedios. Los datos en mapas son hojas de ruta a la acción; los promedios nos conducen al análisis teórico y ahí nos quedamos inmovilizados sin saber como modificar "situaciones generales".

\section{Todo recurso que el Estado des- tina al territorio produce efec- tos}

El recurso que el Estado distribuye (económico, material, infraestructura, humano) y que baja al territorio debe ser evaluado y administrado en términos de impacto comunitario. Aquí sería importante realizar una distinción sobre el rol estatal en las políticas sociales.

Desde los Estados Nacionales es imposible construir intervenciones adaptadas a las circunstancias particulares de cada territorio, sobre todo en países extensos y heterogéneos como lo son muchas veces los nuestros. Es por eso que las ciudades, grandes y pequeñas, tienen el desafío de crear "desde abajo" alternativas a la medida de su gente y capturar esos recursos que llegan desde otros niveles del Estado para distribuirlos de la mejor manera posible en términos de impacto comunitario. ¿Qué inversión es la más útil desde las perspectivas de una comunidad local para trabajar en los lugares de la ciudad más pobres?

- La que ofrece la mejor infraestructura comunitaria: escuelas dotadas de equipamiento de calidad para atender a la población que precisa educación integral, preparadas para los aprendizajes de las distintas disciplinas; jardines de infantes que brinden educación temprana localizados en los barrios más necesitados, con capacidad de recepción de matrícula, y como en caso de las escuelas de otros niveles, con los mejores docentes, para que las mamás puedan ir a trabajar dejando a sus hijos en lugares donde reciban adecuada atención; universida- des públicas a las que pueda acceder el vecino sin costo; centros recreativos y clubes de barrio que tengan oportunidad de prácticas deportivas al alcance de los chicos, adolescentes y jóvenes que no pueden pagar cuotas; playones polideportivos dotados de programas, profesores y supervisión, para ocupar las horas de ocio con esquemas que desarrollen los aspectos físicos y formativos de la población infantil; hospitales y centros de atención primaria de la salud bien equipados, con horarios, profesionales, insumos suficiente al alcance de todos.

- La que dota de la misma inversión en iluminación, infraestructura sanitaria de agua y cloacas, obras viales, acceso al transporte público, que al resto de los vecindarios.

- La que ayuda a que el espacio público de parques, plazas y paseos de los sectores más humildes ofrezca idénticas condiciones de oferta de juegos, mobiliario urbano, limpieza y un lugar lindo para compartir el tiempo de ocio, salvando sin diferencias, la realidad que a veces generan viviendas como hábitats caracterizados por problemas de espacio y superpoblación.

- La que acerca los servicios públicos (energía, agua potable, cloacas, gas natural) para que las familias tengan buena calidad de vida.

- La que mantiene en los barrios más humildes la limpieza y prolijidad del espacio comunitario que caracteriza a los barrios de mayor nivel socioeconómico.

- La que invierte en capacitación laboral generando oportunidades para la población que necesita estar habilitada para poder insertarse en el mercado de trabajo, lo que les permitirá a futuro valerse por sus propios medios.

El Estado también es responsable de generar los mecanismos que permitan que estas obras y servicios sean accesibles para aquellos que no los pueden pagar con la misma rapidez o facilidad que el resto de la comunidad, pero que los necesitan imperiosamente.

Este tipo de intervenciones del Estado contribuye a desarrollar con el tiempo equilibrios más duraderos que la entrega de subsidios. No se pone en cuestión el rol del Estado en la cobertura de las necesidades de la población, pero reforzar las intervenciones integrales en desarrollo urbano, trabajo, educación, cultura, salud, deportes y prestación de servicios, tiene un impacto más saludable para la comunidad. De esa forma, se va disolviendo el vínculo que parecería unir de manera irremediable 
la política del Estado a la entrega de algo: un subsidio, una ayuda, un objeto. Un Estado que da más en subsidios directos no es necesariamente un mejor Estado. El clientelismo a la larga o a la corta, incapacita.

El Estado debe ser cuidadoso en el diseño de sus Programas: que exista un Programa de Atención de... no siempre equivale a que sea ése el problema de la gente. En los lugares donde se pone el dinero por delante de los problemas, se corre el riesgo de instalar circuitos perversos de dependencia. Ese dinero se transforma en un ingreso regular y entra en la lógica de las oportunidades económicas del grupo familiar.

Hay familias que reciben del Estado ayudas cruzadas y múltiples por falta de coordinación entre los distintos niveles y por la supuesta problematicidad de sus integrantes: pensiones, asignaciones, tarjetas alimentarias, programas sanitarios. Incluso se construyen complejos índices de vulnerabilidad, que son puertas de ingreso de las familias a situaciones de diagnósticos que no son funcionales, es decir, no indican por dónde salir del problema. Allí las familias quedan cristalizadas como en un retrato a largo plazo.
Las familias son entrenadas? sin quererlo ? para detectar dónde pueden conseguir fondos y se transforman en recolectores de este tipo de ayudas. En la familia generalmente se busca trabajar, pero se vive y se respira la falta de oportunidades dignas. Por eso es vital la regulación gubernamental de la esfera económica, el monitoreo de la economía, el cuidado por sostener las fuentes de trabajo existentes, la generación de nuevas, y el acompañamiento con adecuadas políticas fiscales. La resolución de fondo de la cuestión social necesita de una mirada más amplia que la de políticas paliativas. Los subsidios son respuestas a corto plazo. El Estado, con sus políticas, es responsable de cómo hace sociedad.

\section{Referencias}

Brofenbrenner, U. (1986). La ecología del desarrollo humano: experimentos en entornos naturales $y$ diseñados. Paidós, Barcelona.

Jullien, F. (1996). Tratado de la eficacia. La inteligencia de hacer posible lo que parece inalcanzable. Perfil, Buenos Aires. 